10. Webb JG, Mack MJ, White JM, Dvir D, Blanke P, Herrmann HC, et al. Transcatheter aortic valve implantation within degenerated aortic surgical bioprostheses: PARTNER 2 valve-in-valve registry. J Am Coll Cardiol. 2017; 69:2253-62.

11. Grubitzsch H, Galloni M, Falk V. Wrinkles, folds and calcifications: reduced durability after transcatheter aortic valve-in-valve replacement. J Thorac Cardiovasc Surg. 2017;153:266-8.

12. Dewey TM, Herbert MA, Prince SL, Bowers BS. Influence of surgical volume on outcomes in low-risk patients having isolated surgical aortic valve replacement. $J$ Thorac Cardiovasc Surg. 2020 [In press].
13. Tam DY, Rushani D, Fremes SE. Commentary: when less is not more-volumeoutcome relationships in aortic valve replacement. J Thorac Cardiovasc Surg. July 25, 2020 [Epub ahead of print].

14. Tam DY, Dharma C, Rocha RV, Ouzounian M, Wijeysundera HC, Austin PC, et al. Early and late outcomes following aortic root enlargement: a multicenter propensity score-matched cohort analysis. J Thorac Cardiovasc Surg. 2020; 160:908-19.e15.

15. Midha PA, Raghav V, Condado JF, Okafor IU, Lerakis S, Thourani VH, et al Valve type, size, and deployment location affect hemodynamics in an in vitro valve-in-valve model. JACC Cardiovasc Interv. 2016;9:1618-28.

\section{Commentary: Management of bioprosthetic valve failure- strategic planning for the future}

\author{
Sameer A. Hirji, MD, MPH, ${ }^{\mathrm{a}}$ Navyatha Mohan, MD, ${ }^{\mathrm{b}}$ \\ and Tsuyoshi Kaneko, MD ${ }^{\mathrm{a}}$
}

We read with great interest the invited expert opinion by Clark and colleagues. ${ }^{1}$ Treatment of bioprosthetic structural valve deterioration is an increasingly challenging clinical entity, and the authors are to be congratulated for their concise yet extensive overview. We agree with the authors' appraisal of existing literature in that the valve-in-valve transcatheter aortic valve replacement (ViV-TAVR) approach to structural valve deterioration appears to be associated with favorable outcomes over reoperative surgical aortic valve replacement (re-SAVR), at least in the short term. This is in contrast to the existing literature showing good long-term durability of re-SAVR, given that the implanted valve will generally behave similarly to the index

From the a Division of Cardiac Surgery, Department of Surgery, Brigham and Women's Hospital, Boston, Mass; and bivision of Cardiac Surgery, Department of Surgery, Massachusetts General Hospital, Harvard Medical School, Boston, Mass.

Disclosures: Dr Kaneko has been a consultant and speaker for Edwards Lifesciences, Medtronic, Abbott Structural Heart, Baylis Medical, and 4C Medical. All other authors reported no conflicts of interest.

The Journal policy requires editors and reviewers to disclose conflicts of interest and to decline handling or reviewing manuscripts for which they may have a conflict of interest. The editors and reviewers of this article have no conflicts of interest.

Received for publication Feb 7, 2021; revisions received Feb 7, 2021; accepted for publication Feb 8, 2021; available ahead of print Feb 19, 2021.

Address for reprints: Tsuyoshi Kaneko, MD, Division of Cardiac Surgery, Brigham and Women's Hospital, 15 Francis St, Boston, MA 02115 (E-mail: tkaneko2@ bwh.harvard.edu).

J Thorac Cardiovasc Surg 2022;163:1802-3

$0022-5223 / \$ 36.00$

Copyright (c) 2021 by The American Association for Thoracic Surgery

https://doi.org/10.1016/j.jtcvs.2021.02.029

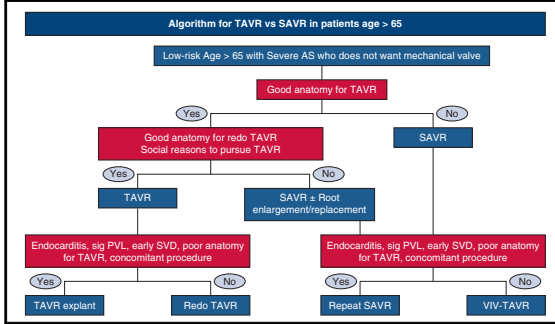

Proposed algorithm for transcatheter and surgical aortic valve replacement.

CENTRAL MESSAGE

Heart teams should systemati-

cally and strategically plan for the

future when determining the

choice of initial treatment strat-

egy between transcatheter and

surgical aortic valve replacement.

bioprosthesis. ${ }^{2,3}$ Furthermore, a recent French study

demonstrated superior 5-year outcomes of lower cumulative event rates in the re-SAVR group, mainly attributed to fewer rehospitalizations for heart failure and lower pacemaker implantation rates. ${ }^{4}$ Unfortunately, all the studies comparing ViV-TAVR and re-SAVR are nonrandomized observational studies with limited long-term head-to-head follow-up and do not adequately risk-adjust for key clinical and anatomical confounders (eg, frailty, risk of patientprosthesis mismatch, and coronary obstruction). Therefore, the need for a randomized control study has been debated, although it will be challenging because of the small population and the need for long-term follow-up. Given the superior short-term outcome and less invasiveness, we believe ViV-TAVR is here to stay, but the long-term outcome should be carefully assessed. 


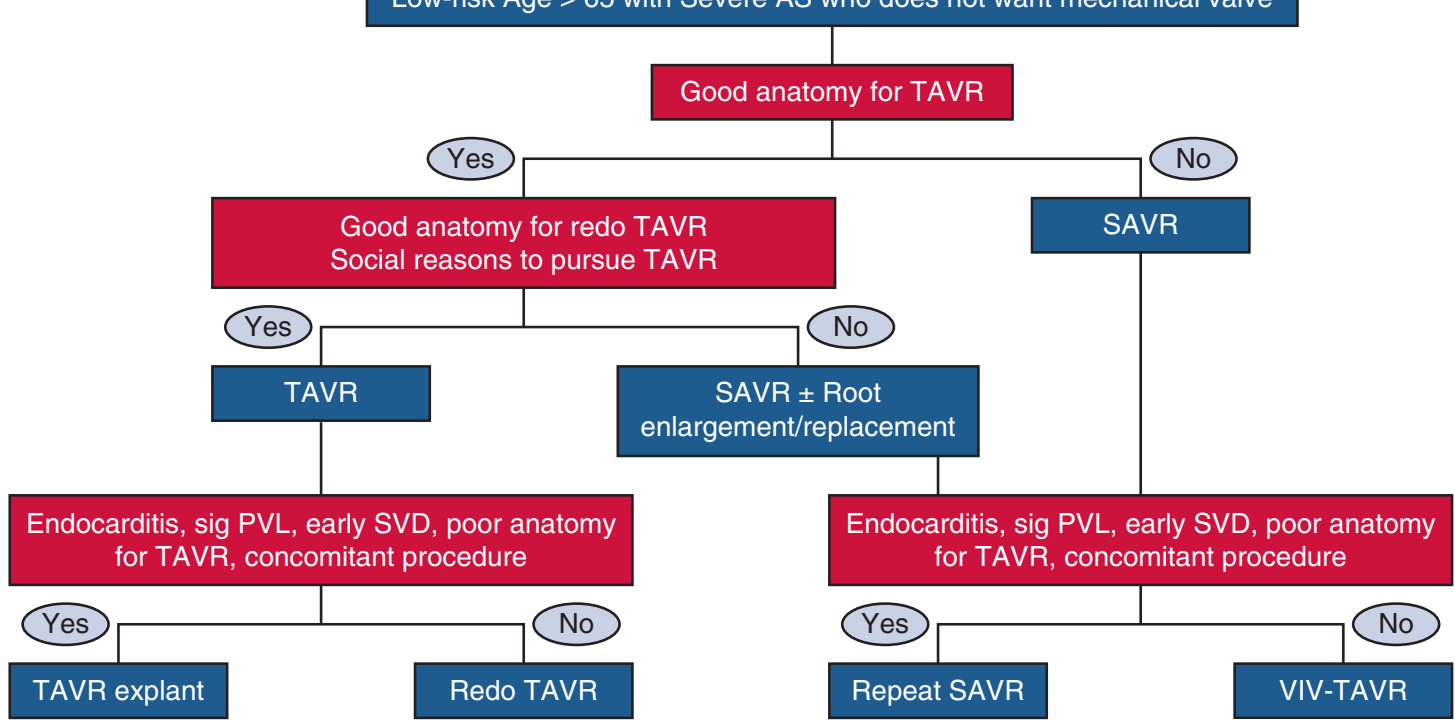

FIGURE 1. Algorithm for transcatheter aortic valve replacement $(T A V R)$ versus surgical aortic valve replacement (SAVR) in patients aged 65 years. $A S$, Aortic stenosis; $P V L$, paravalvular leak; $S V D$, structural valve deterioration; Sig, significant; $V i V$, valve-in-valve.

Although the emerging evidence on repeat interventions, such as ViV-TAVR, repeat TAVR, and TAVR explant, has provided useful data for the multidisciplinary heart teams, ${ }^{5-7}$ the choice of treatment between SAVR or TAVR at the index intervention is extremely critical yet nuanced, especially for young patients. We often gauge the success of these procedures based on 30-day or 1-year outcomes, but as the concept of lifetime management of the valvular disease expands, we must also learn to strategically plan for the future. Figure 1 shows our proposed algorithm for selecting the intervention of choice between TAVR and SAVR in low-risk patients older than age 65 years. If a patient has unsuitable anatomy for TAVR based on computed tomography, he/she should undergo SAVR. If the anatomy is suitable for TAVR, the feasibility of the second procedure, the repeat TAVR, should be assessed. If the risk of patient-prosthesis mismatch and coronary obstruction risk is high, SAVR with concomitant possible root enlargement or replacement to allow future ViV-TAVR should be considered. ${ }^{8}$ Setting up the index SAVR for the subsequent ViV-TAVR is critical, especially given that the larger surgical prosthesis and the high coronary height has been associated with better survival in ViV-TAVR. ${ }^{9}$ The role of heart teams continues to intensify, so the time is now for us surgeons to start thinking forward and plan for the future at the time of index AVR procedure, particularly in younger, low-risk patients to ensure success at the time of bioprosthetic valve failure.

\section{References}

1. Clark A, Malaisrie SC. Failed bioprosthetic valve approaches: transcatheter aortic valve replacement approach. J Thorac Cardiovasc Surg. 2022;163: 1795-8.

2. Leontyev S, Borger MA, Davierwala P, Walther T, Lehmann S, Kempfert J, et al Redo aortic valve surgery: early and late outcomes. Ann Thorac Surg. 2011;91: 1120-6.

3. Onorati F, Biancari F, De Feo M, Mariscalco G, Messina A, Santarpino G, et al Mid-term results of aortic valve surgery in redo scenarios in the current practice: results from the multicentre European RECORD (REdo Cardiac Operation Research database) initiative. Eur J Cardiothorac Surg. 2015;47: 269-80.

4. Deharo P, Bisson A, Herbert J, Lacour T, Etienne CS, Porto A, et al. Transcatheter valve-in-valve aortic valve replacement as an alternative to surgical re-replacement. J Am Coll Cardiol. 2020;76:489-99.

5. Landes U, Sathananthan J, Witberg G, De Backer O, Sondergaard L, Abdel-Wahab M, et al. Transcatheter replacement of transcatheter versus surgically implanted aortic valve bioprostheses. J Am Coll Cardiol. 2021;77:1-14.

6. Hirji SA, Percy ED, McGurk S, Malarczyk A, Harloff MT, Yazdchi F, et al. Incidence, characteristics, predictors, and outcomes of surgical explantation after transcatheter aortic valve replacement. J Am Coll Cardiol. 2020;76: 1848-59.

7. Hirji SA, Percy ED, Zogg CK, Malarczyk A, Harloff MT, Yazdchi F, et al Comparison of in-hospital outcomes and readmissions for valve-in-valve transcatheter aortic valve replacement vs. reoperative surgical aortic valve replacement: a contemporary assessment of real-world outcomes. Eur Heart J. 2020; 41:2747-55.

8. Harloff MT, Papoy AR, Hirji SA, Percy ED, Yazdchi F, Aghayev A, et al Aortic root replacement to accommodate future valve-in-valve transcatheter aortic valve replacement. Ann Thorac Surg. November 26, 2020 [Epub ahead of print].

9. Ribeiro HB, Rodes-Cabau J, Blanke P, Leipsic J, Kwan Park J, Bapat V, et al Incidence, predictors, and clinical outcomes of coronary obstruction following transcatheter aortic valve replacement for degenerative bioprosthetic surgical valves: insights from the VIVID registry. Eur Heart J. 2018;39: 687-95. 